\title{
An Investigation Into The Impact of Career Guidance on Career Choice of Secondary Students in Botswana
}

\author{
Yewande Rukewe \\ University of Botswana, \\ Department of Educational Foundations \\ Reginald Oats \\ University of Botswana, \\ Department of Educational Foundations
}

\begin{abstract}
This is a qualitative study undertaken through a case study design. The study was carried out to investigate into the impact of career guidance on career choice of secondary students in Botswana. Data was collected from form 5 students, guidance \& counselling teachers and principals at four (4) private senior secondary schools in Gaborone using a focus group interview, individual interviews and a qualitativequestionnaire. The study was inspired by the quest to understand the impact of career guidance and information provided in secondary in determining career choice of students in schools. The Systems Theory Framework (STF) was used as a guide the study. The findings reveal the absence of a robust career guidance programmes and practices in most of the schools. In schools with career guidance programmes, these were found wanting. Students show their awareness on subject combination and requirements for entry into higher institution in their responses. However, majority of the participants did not have enough career information as expected of students at their final stage of secondary education. The study concludes that due to the dynamic nature of career choice and planning process, career decision of students are influenced by various factors and that as such students need career guidance and information in order to make informed and wise decisions. Thus, in light of findings from this study we recommend that systematic guidance programmes which will adequately address the career needs of learners be developed and provided in schools.
\end{abstract}

Keywords: career counselling, student learning, career decision making, secondary education

\section{INTRODUCTION}

Nations and the world generally look up to education as the solution to problems like poverty, ignorance, drought, excessive rainfall, mental deficiency, joblessness, bad governance, poor communication system, hunger and inadequate shelter among other socio-economic problems (Olamide \& Olawaiye, 2013). The path to solving these problems through young people depends upon the amount of success they achieve during schooling especially when it comes to making the right career choices.

Generally, career choice is about making decision on the profession one wishes to pursue in future (Abu Talib \& Tan, 2009). As such career choice is an important but complex decision for students to make since it determines the kind of profession they would pursue and whatever decision they make would have great impact on the society and their lives (Borchert, 2002). A person's profession or occupation plays an important role in life and determines remuneration, friends, lifestyle, social status, physical and mental state (Olamide \& Olawaiye, 2013). 
Students at one time or the other are faced with the task of exploring available career options, make a choice; prepare, commence training and actualize their dreams (Olamide, \& Olawaiye, 2013). This decision-making stage is undoubtedly a critical period, because there is no clear blue print available to students and making a wrong career decision can make or mar one's happiness in life (Borchert, 2002). It is therefore highly important to equip students with appropriate skills to help them make reasonable and satisfying choices (Hellmann, 2014).

In general, studies have shown that as students undertake the process of career choice they are confronted with internal and external factors (Pavel, 2015; Edwards \& Quinter, 2011; Clutter, 2010; Janigo, 2015). Internal factors are those that are unique to each individual such as passion, aptitude and personality traits so personal satisfaction represents the primary motivation; external factors are derived from someone or something outside the individual such as socio-cultural, political and economic considerations.

It was a common practice in the olden days for children to select their parents' profession, where the son or daughter of a medical doctor aspires to become a doctor too (Edwards \& Quinter, 2011). Likewise, parents wish their children take up their profession or something similar (Olamide \& Olawaiye, 2013). Things are different today, with adequate exploration and proper planning, it is possible for anyone to choose a career path that is different from their parents' and be successful with the requisite training, skills and knowledge (Edwards \& Quinter, 2011).

In general, students begin to think about future career when they get to high school and look forward to early entry into occupational world as soon as they complete higher education (Olamide, \& Olawaiye, 2013). Several studies showed that most students in their late adolescent stage in secondary schools, experience anxiety when selecting subjects, and deciding about a career, because they do not have sufficient information about available opportunities (Issa \& Nwalo, 2008; Shumba \& Naong, 2012; Watson, McMahon, Foxcroft, \& Els, 2010; Edwards \& Quinter, 2011). Due to little attention paid to career guidance in schools, students make inappropriate subject selections and select careers without considering their interests, potentials and mental capacity to cope with what is required to pursue such disciplines (Edwards \& Quinter, 2011). According to Shumba and Naong (2012), choosing the right subject combination leading to the right profession can make the difference between enjoying and detesting one's future vocation. Unfortunately, many high school students select subjects and match profession without any genuine reason for their choices (Johnson \& Mortimer, 2002).

For some student it is their unique past experiences, how they perceive their environment and work experience that directly or indirectly influence the career choices they make (Borchert, 2002). For others, their choice depends on the availability of education advancement opportunities, availability of employment after graduation, high earnings and prestige attached to such profession compared with other (Wally-Dima, 2013). According to Edwards \& Quinter (2011), while most student follow their parent's choice for them, financial rewards and prestige, some still genuinely pursue their desired profession regardless of remuneration. Students' desire for particular jobs have also been found to be influenced by the emergence of information technology, globalization, socialization, role model, social support, and job competition (Edwards \& Quinter, 2011).

Choosing a career is one of the most important decisions adolescents in Botswana are confronted with in high school and many are overwhelmed at this stage because they do not have sufficient information to enable them to match their personal attributes such as interests, 
skills, values and personality to the world of work. Megkwe (2010), stated that there is no effective implementation of career guidance programs for students in Botswana that could expose them to career options, type of academic and occupational training required to succeed in the workplace, current information on job opportunities among other things. According to Issa \& Nwalo (2008), a successful career without planning cannot happen by chance. People who really get what they want in a career do so because they define their objective, plan and assume personal responsibility for implementing and following these plans (Otukho, Nabie \& Godia, 2017). The situation in Botswana schools is that, only a few schools implement guidance and counseling program, which runs only for thirty-five to forty minutes per week or once in a month. It follows that most students do not have enough access to career guidance and counseling resources, they lack confidence and are unable to appraise themselves to know their strengths and weaknesses, resulting in uncertainty about their future career.

Other challenges which hamper the smooth running of career guidance programs required to address needs of learners in Botswana schools, include lack of trained personnel to handle and deliver effective career services, inadequate resource materials like audio-visual tapes, career handbook and professional talks (Megkwe, 2010). Even the annual career fair which ought to disseminate information to students on available programs that are marketable in Botswana and expose them to the realities of the workplace, are of little benefit to students (Megkwe, 2010).

It has been observed that students in Botswana do not have total control over their choice of subjects; parents, teachers and school counselors impose subjects that they do not have interest or aptitude forgetting that such selections would affect performance and eventually shape their future career choices. Wrong choice of subjects and career decisions have been shown to contribute to majority of students' drop out from institutions of learning (Ketshepile, 2016). Botswana students consider government scholarship or parents' income when selecting a field of study because it determine whether or not a student will proceed to a higher institution for training to fulfill their dreams. The 1994 Revised National Policy on Education (RNPE), which is the current policy of state education, restates the goals of education for Kagisano and adds the goal of preparing Batswana for transition from a traditional agro-based economy to the industrial economy that the country aspires to. In this process of transition, the nation is faced with shortage of skilled personnel. In recent years, there have been concerns from stakeholders that there is a mismatch of skills in the country as tertiary institutions produce graduates not needed by the industry hence the growing unemployment rate (Ketshepile, 2016). It has become necessary to review students' sponsorship for careers that will benefit and change the economy. The areas of interest include the agricultural sector, creative industries, mining, manufacturing, health sector, information technology and tourism, among others (Ketshepile, 2016).

Job opportunity after graduation is another factor Botswana students consider when deciding on careers. It is observed that because most students have their primary, secondary and higher education in Botswana, they also want to get employed in their country, so, students aspire for professions that have employment opportunity in the country.

Students are also attracted by the high financial benefits and prestige attached to certain professions. Students' gender and personality has substantial effects on student choice of academic and occupational pursuit. Female students are biased against certain fields therefore tend to match their personality with the role and activities they are supposed to play in a given profession to see if they fit. For example, not many female students are found in engineering, sciences and technical fields, political science, and geology. 
The objective of this study was to examine factors that influence career choices among students in private senior secondary schools in Gaborone and career services provided to assist them overcome challenges faced when making decisions.

\section{Statement of the problem}

Megkwe (2010) observed that there is no widespread implementation of guidance and counseling program in senior secondary schools in Botswana which could help students in subject selection, course of study choice, and career development. According to this authors, even the few schools that implement this program lacked trained teachers in the subject to effectively handle the sessions and do not allocate sufficient time. When students are left to themselves, choosing the right subject combination for a reasonable profession can be difficult. Students make career choices without information of the needed subject combinations, skills and personality type match. Consequently, when these individuals gain admission into tertiary institutions, they experience poor academic performance and are forced to change courses of study or drop out of school altogether. The nation can ill afford such a situation given that resources are scarce to sponsor students who would not complete their training and contribute to national development either as employers of labor or being gainfully employed. From anecdotal evidence, students in secondary schools in Botswana do not have control over subject selections because parents, teachers and counselors have the final word (Ketshepile, 2016). When such crucial decisions are based on the convictions of others, students could end up not only studying courses that they are not cut out for but face the consequence of not fulfilling their potentials. The impact of the lack of interest in the course of study on the individual could be absenteeism from classes and disciplinary problems such as substance abuse.

As students are drawn to certain careers, they tend to shun the others that are less appealing leading to a decline in enrolment in training institutions and raising the risk of rationalizing trainers/courses in citadels of learning. The impact is that some disciplines would lack enough manpower thereby worsening the imbalance in the workforce and the country's reliance on foreign specialists in such scarce skills. As there is little preparation for career choices in our schools, students would not be encouraged to explore various options thoroughly, raising the risk of making wrong choices. Inappropriate career decisions have other future penalties such as job dissatisfaction, poor work performance, low employee morale, emotional depression, and worsening unemployment rate. There have been various studies globally to look into career choices of senior secondary schools students and motivating factors but local reports are scarce and none has been done on private school. It is therefore important to carry out this study in selected private schools in Gaborone, Botswana to investigate the decision-making processes of these students and make recommendations that would be beneficial to all stakeholders.

\section{Objectives of the study:}

- To determine the impact of career guidance and information provide in schools on career choice of secondary school students in Gaborone.

\section{THEORETICAL FRAMEWORK}

In this study the Systems Theory Framework (STF) was used as a guide to understand the origins of career choice and counseling and the various dilemma students face in making a wise career choices. STF was first published as metatheoretical framework in 1995 (Patton \& McMahon, 2006). These theory since publication and review over years has been used to establish theoretical framework in the international career development literature and in the international career development arena. STF has been widely accepted by career counselors, 
experts and used to understanding career decision-making and development, career assessment, career counseling, career education and more recently in career research.

The preference of STF as the appropriate theoretical lens to understand various internal and external factors that influence career choice and development is because it recognizes the contribution of all past theories and covers a wide range of intrapersonal influences, some which have received considerable attention by career theorists and others that is not well understood within the theoretical literature, meanwhile their influence can be profound (Patton \& McMahon, 2006).

STF postulates that because individuals do not live in isolation, career choice and development is an open system that is subject to influence from internal and external factors and may also influence that which is beyond its boundaries (Patton \& McMahon, 2006). The STF presents career choice and development as a dynamic process or systems, where factors that influences are located within the context of time - past, present and future, all of which are interrelated meaning the past influences the present, and together past and present influence the future. These influences might change as time passes.

The theory has been prove to link theory and Practice easily, career counsellors have used STF for career assessment, counseling models and career solution-focused strategies (Patton, McMahon, \& Watson, 2006; McMahon \& Watson, 2006). The STF allow the researcher to administer instruments, interpret the data and analyze qualitative data to provide information on the perceived factors that influence career choice and development. It is also suitable for this study because of its application in either individual or group interventions and multicultural settings even at broader system level influences (McMahon \& Watson, 2007; Patton, McMahon, \& Watson, 2006).

\section{LITERATURE REVIEW}

The choice of careers, subjects, courses of study and the subsequent career paths to follow are a great challenge for many students because they lack adequate information (Issa \& Nwalo, 2008). According to Abu Talib and Tan (2009), lack of information hinder students from choosing the right course of study.

Guidance and counseling is a professional field which provides range of activities, programs and services on educational, career, social and personal guidance (Mesa, 2013). These services address individual needs, assist them to understand their personality, environment and develop the ability to making informed decisions (Eyo, Joshua \& Esuong, 2010).

It is imperative that students have knowledge of themselves, current information on their prospective careers, environments and job availability at the point of decision-making (Mesa, 2013; Sarwar \& Azmat, 2013). The required knowledge can only be acquired through guidance and counseling, supportive family background, and positive role modeling among others (Mesa 2013). Schools that are supposed to play a leading role in providing career information and counseling are not fulfilling their responsibilities to students (Mapfumo \& Nkoma 2013; Sarwar \& Azmat 2013).

The role of career guidance and counseling in schools according to Adegun and Aremu (2013) and Mesa (2013), is to assist students in subject selection, develop self-awareness, knowledge on career options, learn career choice skills, awareness of post-secondary challenges, job search skills, cope with job stress, learn application of problem solving skills and apprise them with possible mistakes in decision made (Mesa, 2013). Its importance cannot be undermined 
because it provides the needed information, which increases students' confidence to make informed choices (Pavel, 2015).

Onoyase and Onoyase (2009), in their study showed that there was an association between career choice and counseling. They reported that students made wrong selections due to the absence of guidance counselors in the school. Adya and Kaiser (2005), found that career and occupational counseling were lacking or inadequate in high schools; teachers and counselors provide little or no career direction. This result was in agreement with the findings of Olamide \& Olawaiye (2013).

Mekgwe (2010), studied the extent to which the current career guidance program in Senior Public Secondary Schools met the needs of the learners in Gaborone, Botswana and concluded that limited time, lack of trained personnel, lack of key career exploration activities and resource materials in schools hindered effective career service delivery. While Shumba, Mpofu, Seotlwe and Montsi (2011), found that since school teachers were only trained to teach all curriculum subjects except Guidance, they were ineffective in guidance program in Gaborone schools. The authors recommended that successful implementation will require personnel with sound knowledge and skills of career counseling.

It is evident that what goes on in Botswana schools is a replica of the situation in some other countries. Truong (2011), in his article on Career Education Policy and Practice in Ontario High School reported students' dissatisfaction with time and number of sessions with counselors. School counselors expressed high student-counselor ratios, extra responsibilities and student low attitude towards counseling sessions. The study suggested students' and counselors' change of attitudes toward career planning education. Witko et al (2005), revealed that students in all grades acknowledged the presence and importance of career counseling services but desired more information about available courses, post-secondary education and other support for career planning. The authors suggested the need for a comprehensive curriculum that provided information on students' career development. Similarly, Bloxom, Bernes, Magnusson, Gunn, Bardick, Orr and McKnight (2008), in their study among grade 12 students in southern Alberta, Canada confirmed the availability of career development programs that did not meet their needs and called for an effective career and life planning educational programs. Programs that will help them pursue professions they are passionate about, consider individual interests and abilities, provide information on financial help for education advancement, and information about post-secondary education.

The situation is not different in Nigerian schools. Oluwatosin (2016), in his study on stakeholders' perception of guidance and counseling services in secondary schools pointed out that majority of students, teachers and parents were aware of the relevance of counseling to students but admitted that the services provided were ineffective due to lack of qualified human and material resources, while some schools do not have counseling service. This contradiction implied that counseling services were given more attention in some schools than others. The study suggested that government should initiate a policy through the Federal Ministry of Education, to provide minimum standard for the provision of counseling service in all schools in Nigeria. Getange and Sagwe (2016), reported that students received little or no career guidance due to inadequate training of the teachers, few career guidance sessions and in some schools none were organized. In the same study, teachers' responses showed that students' career awareness and aspiration were low. Teachers agreed that an increase in career guidance sessions, materials and trained resource persons were necessary. Ojiah, Apeh and Apeh (2015), found that guidance and counseling services are not available in all schools and recommended that stakeholders in education should make efforts to make the extend the 
services to all schools and ensured that counselors were doing their jobs through regular monitoring. Gichohi (2005), said that there had never been serious efforts to help students make right career choices. Many schools depended on the 1989 career information handbook, whose information had become obsolete.

Mesa (2013), found that students to a large extent do not have access to career information to make realistic plan for their future, while some are unaware of career and guidance training opportunities at various levels of post-secondary schools education. It was worse in the rural schools which have constrained access to career guidance programs and resources such as trained teachers, published articles, media, and Non-Governmental Organisations (NGOs). In South Africa, career opportunities are unevenly distributed, career programs are provided for privileged groups and the majority of black persons receive nothing (Maree, 2009). Similarly, a recent study by Bojuwoye and Mbanjwa (2006), found that students from disadvantaged schools made wrong choices because they lacked career information or unsatisfactory career counseling services. Mapfumo and Nkoma (2013), in their study to assess the presence of guidance and counselling services in Zimbabwean high schools found that students from mission and government schools indicated awareness of guidance and counseling services, while students from rural schools do not have access due to lack of material resources, qualified career counselors and poor socioeconomic status of parents. The report also showed negative attitudes of school authorities to guidance services and counselors in particular.

Edet (2008), reported negative attitude towards vocational guidance services in Nigeria. The study pointed out that school authority's negative attitude constituted the greatest obstacle to the success of career guidance and counseling programs and activities in schools. Mesa (2013), further explained in his study that counselors are not regarded and treated as part of the school system, because they see the services of the counselors as unnecessary and treated as irrelevant.

Tiego and Kamore (2015), reported that Guidance and Counseling programs were not effective in schools because of inadequate training of personnel, less time and lack of support from the administration. In schools where there are guidance and counseling programs, the focus are on students' discipline rather than career information. Likewise Chireshe (2013), reported that most Zimbabwean secondary schools do not have counsellors and the few that had were involved in HIV \& AIDS counseling and other issues such as unwanted pregnancy, sexual abuse, drug abuse, school violence, etc. This result implied that students do not have information on career decision process which are needed to make wise selection. Mogbo, Obumneke and Anyachebelu (2011), revealed that only 29 percent of girls received support from career counselors on career decisions. The study further revealed that teachers and counselors were comfortable counseling on other issues than career planning and development, probably because they do not have sufficient career guidance training. In Pakistan, respondents agreed to lack of proper career counseling in schools and revealed that the media played a major role in helping students in making their selections (Sarwar \& Azmat, 2013).

Contrary to negative report on career guidance and counselling, some studies have shown positive perception of guidance services. Kimiti and Mwova (2012), data revealed the presence of career guidance programs in all the twelve selected schools in Machakos and Kitui Counties, Kenya where $89.5 \%$ of the students indicated that the provision of career guidance and information helped them in choosing their career. Also Amoah, Kwofie and Kwofie (2015), reported that students strongly agreed that all forms of career guidance and counseling provided by their school influenced their decisions. It was therefore recommended that frequent career programs be provided to support students make well informed choices. Dabula 
and Makura (2013), in an Eastern Cape study revealed that the program helped students overcome their fears, confusion and lack of confidence in the process of making career choices in their respective schools. Eyo, Joshua and Esuong (2010), investigated the attitude of secondary students towards guidance and counseling services in Cross River State, Nigeria. The study revealed that students' attitude towards guidance and counseling services were positive.

Koech et al (2016) suggested that exploring career options through guidance and counseling before committing to a career increases future success and satisfaction. Mesa (2013) further argued that to reduce unrealistic career choice among school students and the number of frustrated people in the society, it was imperative that effective career program be provided.

\section{Research Design}

\section{RESEARCH METHODOLOGY}

According to Pride and Ferrell (2008), research design is a structured plan for obtaining data from a target population, analyzing and interpretation of all the gathered information. A case study approach was ideal for this study. Qualitative research design was used to collect data. This design according to Cooper and Schindler (2011), provides current and precise description of a problem at a particular point in time based on gathered information. This design allowed an in-depth study of students, counselors and principals (school heads) on factors that influenced career choices among private senior secondary school students in Gaborone and the impact of career preparation services.

According to Patton and Cochran (2002), qualitative approach seeks respondent's perspective over an issue or problem. Hence, qualitative method would encourage participants to freely express their feelings, emotions and knowledge on motivating factors and the impact of career guidance and counseling programs. Furthermore, qualitative approach gives a researcher the opportunity to interact and dialogue deeply with participants during data collection, allowing further probing to get rich information. This key advantage of the approach allowed the researcher to collect and analyze data as perceived by participants.

\section{Sampling procedure}

Sampling is the selection from a well-defined population that is representative in all possible ways. Four schools were randomly picked from the list of private schools to take part in the study. Simple random sampling was used for students' selection because it allowed the selection of each unit independent of every other unit. The students were randomly selected from all form 5 classes to ensure that there was no bias using the class registers. Career counselors/teachers and school principals from each school were purposely selected. It is believed that the findings from the four selected schools are enough to unveil perception and experiences on career choice and planning in private schools in Gaborone. Each interview lasted between 45-60 minutes. Creswell (2013), asserted that a whole population is very large and may not be practically used in a study, therefore, a manageable size can be used to represent the total population. Sample size is the subset or smaller unit selected from the population for study. In the opinion of Bloor (2001), focus groups consisting of 6 to 10 participants are considered suitable for producing answers to research questions. For this study, 12 learners were randomly selected to participate in the focus group interviews at each school. In total, there were 4 different focus groups with a total of 48 students representing the target population in the interview. Also, four career teachers and four principals, one from each school, automatically qualified for inclusion in the study. This size was a fair representation since the population share similar characteristics. 


\section{Data collection procedure and instrument}

In qualitative research, people's words, actions and archives from interviews, observations and artifact analysis (documents analysis, photos, written or text materials) are sources of data collection. The data could be gathered from primary or secondary sources. Instruments such as observation, in-depth interviews and group interview formed the primary sources of information, while relevant documents, tapes (video or audio recording) and photographs are secondary sources of data.

For this study, focus group interview, one-on-one interview and qualitative questionnaire were used to collect data. Focus group is a type of qualitative research interview where a small group of homogenous people are brought together to discuss a specific topic for the purpose of obtaining relevant information (Dilshad \& Latif, 2013). Interview allows one to probe and obtain in-depth information from participants which might be difficult or impossible to get from a yes or no response questions or other means of data collection. It allows participants to express themselves freely without being constrained by questions with predetermined answers. It is an excellent way of asking individuals or group of people to freely express their opinions, interests, experience, perceptions and ideas on a particular issue (Schostak, 2005). Scheduled face-to-face focus group interviews of students and individual interview with career teachers unveiled their perceptions and experiences on career choices and planning. The study used open-ended qualitative questionnaire technique to collect data from principals of each selected private schools. Although it is an uncommon method in qualitative studies, it was used to save time knowing that principals being busy do not have time for long interviews. This approach was also considered because of the small population of participants and information required was straightforward.

Prior to actual collection of data from participants, the researcher applied for permission to carry out study from the University of Botswana Office of Research and Development (ORD). After receiving approval, the researcher conducted a visit to establish a friendly rapport with the school authorities, students and career guidance counselors.

Assent and consent forms were given to potential participants and their parents to complete as evidence of agreement to voluntarily take part in the study. These forms described in brief the research project: objectives, selection criteria of subjects, assurances that the information given would be treated with utmost confidentiality and anonymity. Permission to use tape recorder during the interview was sought from participants. It was also made clear to the participants that they can voluntarily withdraw at any point in time when they are no longer comfortable with the interview.

The researchers reserved appointments for the dates to interview and administer open ended questionnaire to participants. Counselors or teachers in each school were present at the interview sessions to ensure that the procedure was fair, without bias, and that ethical requirements are met. The participants were asked the language they preferred for the interview and the most comfortable location to hold the meetings. The interview was conducted with the assistance of trained research assistants.

The interview was guided by an outline of questions focused on the research questions and constructed in clear words for ease of understanding. Due to time constraint, each group was interviewed once using an interview guide to pose the same number questions to all participants in each school for 45-60 minutes as agreed with the school administration. Career guidance teachers in each school were also interviewed using similar schedule at their offices. 
Interview proceedings were audiotaped and later transcribed. Also there were handwritten notes by the researcher during the interview on the atmosphere, sitting arrangements, timing, room setup, interaction, freeness and non-verbal cues as additional data sources. The wording of questions for interview guide and open ended questionnaire were identical for career counselors and principals to facilitate easy data analysis. The participants were asked if they had questions or additional information that was omitted during the interview. Then the participants were thanked and the session ended.

\section{Ethical protocol for data collection}

In research, ethics are principles that guide researchers' conduct and relationship with participants (Creswell, 2013). Botswana has a standard procedure that stipulates that before pursuing any research in the country, permission should be sought from the office of the Permanent Secretary of the relevant ministry. As a matter of fact, permission was obtained from the Permanent Secretary, Ministry of Education and Skills Development for collection of data in the sites identified through the office of ORD-University of Botswana. After receiving permission, all selected schools were notified in writing and visited for permission to conduct the research. These actions were influenced by the fact that informed consent of the participants is a pivotal aspect of research ethics (Mills, 2003). Somekh et al. (2005) concurred that ethical issues are centrally important in social research because knowledge confers power. Additionally, respondents were made aware that they are free to withdraw their consent or withhold any information or are even discontinue their participation in the study at any time. Along the same vein, the matter of confidentiality of respondents was emphasized to respect their decisions about dissemination of the information obtained. The learners were reached through the school administration during school hours and therefore were easily accessible.

\section{RESULTS AND DISCUSSION}

Participants were asked whom they approached for career guidance and information, guidance and counseling in their schools. They were asked to rate their level of career knowledge and what their career needs are and how they can be met. This question sought to know how much information they had, sources and how they set out to actualize their dreams. On whom they approached first for advice, most indicated that they approached their family members first, mostly their parents and siblings. $\mathrm{S}_{7} \mathrm{FG}_{2}$ said:

"I talked to my brother who is an aeronautical engineer, who advised me that if loved any profession I should go for it. He advised that I should have two or more options in my subject combinations and to explore other options. My dad has been most helpful in giving information."

It was noted that female respondents tended to approach their mothers first for guidance. Two of the female responders said: "I talked to my mum and she has been the most helpful" ( $\left.S_{4} F G_{4}\right)$.

"My mum was most helpful, she encouraged me by buying me books" ( $\left.S_{9} F G_{1}\right)$.

A number of them also mentioned that role models in the chosen field were helpful for guidance. Surprisingly, these role models were their parents.

$\mathrm{S}_{5} \mathrm{FG}_{3}:$ "My dad is my role model, he also does farming alongside real estate business, and advised that I give equal attention to my options."

$\mathrm{S}_{3} \mathrm{FG}_{4}:$ "I approached my father, because I wanted to follow in his footsteps and I get all my inspiration from him. My late cousin was the most helpful by providing lots of information on medicine being a medical practitioner." Witko, Bernes, Magnusson and Bardick (2005) in their study among senior high school students in Southern Alberta Canada found that students were 
comfortable approaching their parents for help with career planning, followed by relatives, role model in the field, friends, school counselors and teachers, in that order. Another study on career options also indicated that students sought help from parents more than their teachers (Oyamo \& Amoth, 2008). Students approached their parents and siblings because they appear to be the only one available and in a position to provide career-related information and support.

On how the schools have been of help to learners' career planning and development, it was evident from the responses that schools gave minimal attention to this subject. Most of the students' reported that there was no guidance and counseling on various career options in their school. The students expressed that they knew too little or nothing about a wide range of professions with the exception of the traditional vocations such as law, medicine and engineering. Their response was in agreement with Issa \& Nwalo, 2008; Abu Talib \& Tan (2009) that, the choice of subjects, courses of study and the subsequent career paths to follow are a great challenge for many students because they lack adequate information.

In response to the question about what services schools provided, $\mathrm{CC}_{3}$ stated that:

"Students are exposed to career counseling from form two. A 35-minute counseling session is organized with each class once a week. The sessions provided information on various career options, personal and societal benefits, kind of training required, course duration and tips for success in any given profession. Students are advised to build their career around their mental strengths and those who are performing below average in selected subjects are advised to change to what they can cope mentally with and choose careers based on their abilities."

In addition to $\mathrm{CC}_{2}$ comment $\mathrm{SP}_{2}$ stated that:

"We advise students to be clear about the reason for choosing a particular career, how to achieve it, the benefits and challenges involved. Students are encouraged to do job shadow during holidays to see what happens in the work place, explore various options available and remunerations to prepare their mind."

$\mathrm{CC}_{4}$ who is a female science teacher responsible for career guidance and counseling duties expressed the following:

"Students are guided on subject selection as from form two. We get an idea of various career paths of interest to students and invite professionals to talk to them from time to time before they write their final examination."

This researcher attended one of such sessions which featured two professionals from different fields who spoke for 30 mins each on their disciplines, various options, professional examinations, training institutions and possible challenges. $\mathrm{SP}_{4}$ of this same school added that:

"University lecturers and professionals in various fields are invited to give career talks to students on admission requirements to tertiary institutions, years of study and success tips in different courses. Various career options, qualifications, professional examinations, employment opportunities, work structure and job search are also discussed. This enable students to build on information they already have and prepare their minds for post-secondary education and provide a platform to have their questions answered".

$\mathrm{CC}_{1}$, a senior teacher in charge of examination and counseling duties expressed that:

"Career counseling for students start when they are in form four and the sessions are held fortnightly. During each session, students are advised on how to choose subjects 
carefully in line with their aspirations. Students are introduced to various career options offered in local and international universities, requirements for entry and various job opportunities."

$\mathrm{SP}_{1}$ stated that: "Career choices are majorly the decision of students and parents. Our teachers just serve as guides. We advise them to choose courses that are required in the labor market. We also impress upon them to enquire about scholarships opportunities."

In the last school studied, $\mathrm{CC}_{3}$ responsible for guidance and counseling reported that: "The school does not have any counseling unit therefore students are left to seek career information and guidance on their own. The internet option is presented to them to browse available courses in universities within and outside the country and admission requirements."

When students were asked on support they received from schools, most of the respondents indicated that they do not have a structured career guidance and counseling unit and that they are randomly advised by their teachers on subject selection and how to study hard to make good grades. $\mathrm{S}_{2} \mathrm{FG}_{4}$ stated that: "We just approach teachers we are comfortable with for guidance, there is no teacher responsible for career guidance in our school."

In the same vein, $\mathrm{S}_{10} \mathrm{FG}_{1}$ said: "We get advice from subject teachers on how to improve academic performances generally. Our examination coordinator gives us information on the entry requirements and university cut-off points for various careers. There is really no career counseling service." $\mathrm{S}_{1} \mathrm{FG}_{2}$ also claimed that, "The school does not guide us on our career choices. It is our responsibility to research on this subject".

Students, teachers, counselors and principals' responses revealed that only one out of the four schools has an office dedicated for Guidance and Counseling. The other schools assigned teachers to guide students on subject combination for various careers, examination preparation and organized career talks. This finding is in agreement with Alexitch et al., (2004) and Bardick et al. (2004) that most secondary schools do not provide adequate career counseling services for learners. Schools that have guidance and counseling unit concentrate more on personal, academic and social issues. Schools are supposed to play an important and leading role in providing current and comprehensive career information through their guidance and counseling offices to help students make informed career decisions.

When students were asked to rate their knowledge on the careers they have chosen on a scale of zero to ten (where zero was very poor and ten was excellent), most scored themselves between five and six. Most teachers and principals interviewed strongly agreed that career services provided by the schools currently do not meet the needs of the students and a lot more needs to be done. The students also asserted that they needed more information on available options, insights into university campus life, educational advancement opportunities, employment opportunities, workplace realities and challenges. This result agrees with Witko et al's (2005), that the more career information students' gets the more engaged they are in the processes of independent and informed career decisions.

Given that lack of information contributes to ignorant and unwise career choices, the findings of this study is worrisome. In general, most respondents do not have sufficient information to make informed decision. At best, they have basic information on subject combinations, required grade point of entry into tertiary institutions within and outside the country, and programs offered in various reputable institutions. It was noted that students do not know 
much about what happens in the university. Most students access information from the internet, newspapers and family members.

There were, however a few participants that displayed gross lack of knowledge by offering very immature responses such as: "I don't know why I want to study law maybe it just the name and money". In another group a student said: "I want to pursue a career in travel and tourism because I like to travel".

Some respondents could be said to aspire for unrealistic occupations. For example, a student declared that she wanted to be a pilot without offering geography and physics which are prerequisite subjects and insisted that she would be a pilot one way or the other. When students were further ask how they plan to achieve their career goals. To a large extent, majority of the responses indicated that coupled with the information they have on admission requirement into various institutions, they were studying hard to ensure that they performed well in prerequisite subjects at the final examinations for admission into tertiary institutions.

$\mathrm{S}_{2} \mathrm{FG}_{4}$ responded that: "I plan on going for an internship on my choice career during my holidays. I've asked my mum to talk to her lawyer-friend to allow me observe and see what goes on in the workplace".

When asked what their greatest career needs was and how they can be met, students from all the groups highlighted more current information on options, planning and development. They also expressed need for guidance on how to discover their talents, abilities and interests in order to make a wise choices.

The respondents called on universities to provide full and current information on the different careers available to allow learners match their interests to several possibilities. They also requested for information about the requirements in various career fields as well as scholarship opportunities. These findings are in line with those of Witko et al (2005) that students perceived not to have acquired satisfactory amounts of information about career planning and required more formal guidance on how to gather, sift through and use available information.

\section{CONCLUSIONS AND RECOMMENDATIONS}

The findings of this study further reveal the absence of career guidance in the schools. This is a lamentable upshot. It was found that due to this condition in most schools visited, majority of the participants did not have enough career information as expected of students at their final stage of secondary education. Regrettably, career information did not seem to be accorded the significance it deserved as career guidance was not offered in most private schools. In schools with career guidance units, their programs, initiatives and practices were inadequate to meet the needs of students.

\section{Recommendations}

The following are some recommendations of the study.

- Career guidance should be taken more serious in schools. As such schools should provide systematic guidance programs which will adequately address the career needs of Senior Secondary School learners in Botswana.

- Comprehensive ways must be explored on how best parents and relatives can be involved in career planning and development of students without conflict of interest or misunderstanding. 
- Tertiary institutions, industries, employers and organizations should be encouraged to provide educational and career information to students.

\section{References}

Bloxom, J. M., Bernes, K. B., Magnusson, K. C., Gunn, T. T., Bardick, A. D., Orr, D. T., \& McKnight, K. M. (2008). Grade 12 student career needs and perceptions of the effectiveness of career development services within high schools. Canadian Journal of Counselling, 42(2), 79.

Bojuwoye, O., \& Mbanjwa, S. (2006). Factors impacting on career choices of Technikon students from previously disadvantaged high schools. Journal of Psychology in Africa, 16(1), 3-16.

Borchert, M. (2002). Career choice factors of high school students (Doctoral dissertation, University of WisconsinStout).

Braza, M. R. S., \& Guillo Jr, R. M. (2015). Socio-Demographic Characteristics and Career Choice of Private Secondary School Students. Asia Pacific Journal of Multidisciplinary Research, 3(4).

Bright, J. E., Pryor, R. G., Wilkenfeld, S., \& Earl, J. (2005). The role of social context and serendipitous events in career decision making. International journal for educational and vocational guidance, 5(1), 19-36.

Brown, D. (2015). Career information, career counseling and career development. Pearson.

Brown, S. G., \& Barbosa, G. (2001). Nothing is Going to Stop Me Now: Obstacles Perceived by Low-Income Women as They Become Self-Sufficient. Public Health Nursing, 18(5), 364-372.

Buser, T., Niederle, M., \& Oosterbeek, H. (2014). Gender, competition and career choices. The Quarterly Journal of Economics, 129(3), 1409-1447.

Chemjor, E. J. (2016). Factors influencing the choice of agriculture subject by boys and girls in public secondary schools in Kajiado county, Kenya (Doctoral dissertation, University of Nairobi).

Chireshe, R. (2013). Peer Counselling in Zimbabwean Secondary Schools. International Journal on Educational Science, 5(4), 349-354.

Churchill GA \& Brown TJ. 2007. Basic Marketing Research. 6th ed. Ohio, USA: Thomson South-Western.

Clutter, C. (2010). The Effects of Parental Influence on Their Children's Career Choices (Doctoral dissertation, Kansas State University).

Cooper, D. R \& Schindler, P. S. (2011). Business Research Methods, 11ed. Rochester, New York, NY: Irwin McGrawHill

Cousins, L. H., Mickelson, R. A., Williams, B., \& Velasco, A. (2008). Race and class challenges in community collaboration for educational change. School Community Journal, 18(2), 29.

Creamer, E. G., \& Laughlin, A. (2005). Self-authorship and women's career decision making. Journal of College Student Development, 46(1), 13-27.

Creswell, J. W. (2013). Research design: Qualitative, quantitative, and mixed methods approaches. Thousand Oaks, CA: Sage publications.

Cutler, J. L., Alspector, S. L., Harding, K. J., Wright, L. L., \& Graham, M. J. (2006). Medical students' perceptions of psychiatry as a career choice. Academic Psychiatry, 30(2), 144-149.

Dabula, P., \& Makura, A. H. (2013). High school students' perceptions of career guidance and development programs for university access. International Journal for Educational Science, 5(2), 89-97.

De Vos, A. S. (Ed.). (2002). Research at grass roots: For the social sciences and human services professions. van Schaik.

Dilshad, R. M., \& Latif, M. I. (2013). Focus group interview as a tool for qualitative research: An analysis. Pakistan Journal of Social Sciences, 33(1), 191-198.

Edet, I. P. (2008). Parents and teachers perception of vocational guidance in secondary school in Calabar metropolis - Calabar Cross River State. An unpublished post guidance diploma thesis University of Calabar, Calabar.

Edjah, K., Dare, A. L., \& Danso, L. M. (2007). Factors influencing attitudes of women towards the education of female children. A case study of the Cape Coast munucipality of Ghana. Gender and Behaviour, 5(1), 1072-1081. 
Edwards, K., \& Quinter, M. (2011). Factors influencing students career choices among secondary school students in Kisumu municipality, Kenya. Journal of Emerging Trends in Educational Research and Policy Studies, 2(2), 81-87.

Eyo, M., Joshua, A., \& Esuong, A. (2010). Attitude of secondary school students towards guidance and counselling services in Cross River State. Edo Journal of Counselling, 3(1), 87-99.

Fabea, I. B (2014). Educational 